\title{
20. HOW A SMALL ENTERPRISE OBTAINED WWW EXPERIENCE AT A MINIMUM COST:- A CASE STUDY
}

\author{
J. B. Thompson and S. McCall \\ School of Computing and Information Systems \\ University of Sunderland, \\ Sunderland SR6 ODD, U.K. \\ Tel : (44) 1915152769 Fax: (44) 1915152781 \\ e-mail: barrie.thompson@sunderland.ac.uk
}

\begin{abstract}
$A$ very successful occurrence of technology transfer between a University and a SME (small and medium size enterprise) is detailed. This involved the creation of a World Wide Web site for the organisation and the production of a detailed research report on Digital Commerce on the Internet. The work was undertaken by a postgraduate student following a Masters level "conversion" course in Computer Based Information Systems. Background information relevant to the project and the course is provided. Details of the research and development work are given. Finally an evaluation of what has been achieved is presented.
\end{abstract}

\section{Keywords}

Higher Education, case studies, networks, electronic commerce 


\section{Introduction}

The explosive growth of the Internet during the 1980 s and 90 s coupled with the facilities offered by the World Wide Web (WWW) has provided many new opportunities for the commercial world. Together these two technologies have provided a simple and relatively inexpensive way for businesses to communicate with: other businesses, clients, and the public. They also present a means by which businesses can greatly enhance their sales and marketing efforts. The prime reasons for a business initially establishing a WWW site can be seen to be (McCall, 1997):

- to network and establish a presence,

- to make business information available to potential customers,

- to heighten public awareness,

- to serve existing customers.

Unfortunately, for small and medium sized enterprises (that is enterprises with less than 250 employees and known as SMEs in the UK) there can be major problems associated with the establishment of a WWW site. These are - a lack of experience and expertise in the area and the costs that would be involved in buying in outside expertise. Also such enterprises are often very wary of outside consultants when approaching new technological areas. This is because they are not sure of how impartial the consultant's recommendations may be and what resultant costs may be incurred. This paper documents an alternative approach involving a close link between an educational establishment and a SME which has resulted in very cost effective technology transfer.

At the University of Sunderland we operate a 'conversion' MSc in Computer Based Information Systems. The course takes only graduates from non-computing courses and after the equivalent of 12 months full-time study produces personnel who can operate very effectively in the computing sector. A significant part of the course is devoted to a practical project which is externally sponsored and represents a sizeable real world problem. One of the projects accepted by the University, during the 1996/97 academic year, as suitable for an MSc. Student involved the construction of a Web site for a SME which retailed pine furniture. The company "Principally Pine" was founded in 1990 and at the time of the project had four retail outlets in the North of England. The company primarily wished to explore the possibility of global advertising over the Internet but was also interested in the possibility of digital commerce in the future.

The following sections of this paper provides: some background information on our MSc course in Computer Based information systems, details of the project that was undertaken with Principally Pine, and finally an evaluation of what has been achieved. 


\section{MSc in Computer Based Information Systems}

The MSc. in Computer-Based Information Systems at the University of Sunderland is a 'conversion' course intended for graduates who have little or no knowledge of computing and are interested in gaining a theoretical and practical understanding of the construction of computer-based information systems. The course is distinctive in that it is offered in five diverse delivery/learning modes (Thompson and Edwards, 1995):

1. Full Time over twelve months at the University,

2. Part Time Evening over 33 months at the University,

3. Part Time Day over 24 months at the University,

4. Block Mode over 36 months where formal attendance at the University is restricted to a maximum of four weeks per year,

5. Distance Learning Mode supported by in-house produced videos and related textual material. This mode is offered from approved centres both within the UK and internationally.

The course has a modular structure and operates within a Postgraduate Credit Accumulation and Transfer Scheme (CATS). The course consists of two main elements: a taught element (equivalent to seven months full time study, which has a value of 70 CATS credits at level $M$ ) and an externally sponsored project (equivalent to five months full time study, which has a value of 50 CATS credits at level M). Intermediate awards of Postgraduate Certificate and Postgraduate Diploma are available for students who wish to leave the course during or at the end of the taught part having gained 35 or 70 credits respectively. The detailed aims of the course are to:

1. promote a critical awareness of the natures, roles and limitations of computer based information systems,

2. develop the knowledge, skills and understanding needed to specify, design, implement, document and furnish continued support for an effective computer based information system, either alone or as part of a team.

3. allow the student to consolidate and display skills, knowledge and awareness in a selected application area for computer based information systems and gain experience of implementing such a system.

The project (which is externally sponsored) forms a major part of the course and each student is expected to devote at least 540 hours of work to it. The aim of the project is to extend and develop the student's ability to analyse, specify, design, implement and document an effective computer-based information system which satisfies an organisational need. The undertaking of the project should mean that students will be able to demonstrate their ability to: 
- Plan, schedule, monitor and control the conduct of a substantial piece of research and development work

- Select and critically assess relevant material from original papers and articles, and to extend the lines of research therein

- Apply some of the methodologies developed during the course

- Plan and communicate, both orally and in writing, a programme of work in information system design and implementation.

Students undertake the course for a variety of reasons, for example: to convert to another discipline completely, to add value to an existing degree, to improve job prospects by being computer literate, to change career paths (often after redundancy or an intentional period out of the job market), to provide an entry into research or lecturing in further/higher education, and to gain additional skills relevant to a hybrid manager. The last is particularly true of mature students who undertake the part-time versions of the course (Thompson and Edwards, 1996). In all cases the project provides a major opportunity for the students to concentrate on an area of their choice (they select their project from those available) and gain knowledge, skills and abilities that should enhance their future careers.

\section{The Web project with Principally Pine}

The prime objectives for the project with Principally Pine were:

1. Research and investigate what makes an effective Web site for a company.

2. Investigate how to design a Web site.

3. Determine what Principally Pine want included on the Web site.

4. Create a Web site advertising Principally Pine.

5. Research the implications of digital commerce to a company.

The research undertaken concerning the factors that should be taken into account when designing an effective Web site encompassed both non-technical and technical aspects. The former included factors such as the purpose of the site, its audience and site organisation. The latter included factors that in general relate to page attributes and include length, links navigation, graphics, frames and forms. The prime sources used in the research were the papers and texts by: Bayne(1996), Chen(1997), Gallant(1997), Gantz(1996), Green(1996), Greenburg(1996), Handley and Crowcroft(1995), Oberndorf(1997), Raggett et al (1996), Sachs and Stair(1997), Scheler(1996), Selzer(1997), Tilton (1996), and Wilson(1996). Using these it was possible to compose a general check list (McCall, 1997) which could be used to determine the company's true requirements. Following this example site were developed to demonstrate both good and bad features so that the sponsor within the company could understand more clearly why particular choices had been 
made. Finally the "good" site was modified to incorporate enhancements which were identified during the sponsor's evaluation.

\subsection{User Requirements and Design Outline}

The check list us to determine the company's requirements for the site and the information obtained was as follows:

1. What is the purpose of your site?

The primary purpose of the site is to advertise the products and services of Principally Pine.

2. Are you presenting information?

Yes. The information should be in one place and in full detail.

3. Are you trying to sell a product?

Yes. The products should be easy to scan allowing quick recognition and evaluation.

4. Are you providing a form-based user interface?

No. Principally Pine currently does not have an established mailing list and therefore do not require forms on the Web Site.

5. Who is the expected audience?

A great proportion of the target audience will be home users on relatively low specification computers. The site should therefore be set up in order to cater for these readers. The use of highly technical features, such as 24-bit true colour images, are therefore inappropriate.

6. What sections should be included in your site?

Following requirement analysis with Principally Pine, the following sections were decided upon:
About Principally Pine
Opening Hours
Reason for Success
Shop Locations
Furniture Suppliers
Finance
Special Offers
Delivery

7. The first screen-full of information, on the first page of the site, should have no vital information beneath the bottom of the browser and should capture the reader's attention.

Agreed.

8. Can the content be separated into discrete sections?

Yes. Therefore multiple short pages should be used including a table of contents.

9. Each page should have a recognisable title.

Agreed.

10. The HTML title should accurately reflect the textual page title. Agreed.

11. Are any of the pages of considerable length (Example: over four screenfuls of text)?

No. Therefore internal page links are not required. 
12. Is there any special reason to use landscape page orientation?

No. Therefore use the standard portrait format.

13. All links, should if possible, match the title of the resulting page. Agreed

14. A link should not be a whole sentence or a single word but should be placed within the text as if the link wasn't there at all. Try to avoid the use of "Click here".

Agreed.

15. The description of a link should be in absolute terms rather than using implied destinations, especially if frames are used. "Proceed to Chapter 3" is clearer in terms such as "Back", "Next" or "Return To".

Agreed.

16. Is your site a large, widely used closed system?

No. Therefore a palette of graphical navigation buttons is unnecessary.

17. Are graphics to be included in your site?

Yes. The low technological state of the expected audience dictates the use of 8-bit, 256 colour displays. Also the expected low-bandwidth connection of the audience suggests the use of one large graphic rather than several smaller graphics.

18. Are graphical bullets to be used in the site?

Yes. A small set of bullets should be used repeatedly rather than using a large number only once.

19. Does your site contain a list of similar topics each requiring its own page?

Yes. A frame-based site should be considered. This will give readers the option for any downloads, allows for better navigation and will aid site maintenance.

20. Are forms to be used in your site?

No. They are not appropriate to Principally Pine.

21. Readers should be given the opportunity to send their thoughts on the site. Agreed. A link to an e-mail address will be supplied.

22. The date when the site was last revised should be included in an appropriate international standard.

Agreed.

23. The finished site should be proof read by the sponsor and if possible another person.

Agreed.

\subsection{The Development of the Web Site}

It was decided that two sites should be created. The first site, referred to as a 'dummy' site would not follow the design principles determined during the requirements phase and in some cases would actually go against these recommendations. There were two reasons for doing this:

1. It would demonstrate to the client what could happen if suitable design guidelines are not adhered to.

2. This site could be used to practice the necessary Web design techniques. 
The second site would then be created incorporating the design guidelines determined during the requirements phase. This site would eventually form the working Principally Pine Web site. For both sites a exploratory prototyping approach was used whereby following a number iterations a fully working system was built up stage by stage .

\section{The Dummy Site}

Although this site neglected many of the design feature identified above, the single most disregarded figure was the blatant overuse of graphics. Indeed the site took on average 22 seconds to load, which is far higher than the recommended top limit of 10 seconds. Other design recommendations that were overlooked include the use of "Click here" and whole sentences as links. A copy of this version of the sit can be found at:

http://osiris.sunderland.ac.uk/ cs0jbt/pine/index.htm

\section{The Actual Site}

The evaluation prototype of the proposed Principally Pine site consisted of a titie screen and two pages of the actual site. These were necessary to demonstrate the use of frames and the internal navigation of the site.

The title page contained a graphic of the company's name, a link to the main site, a link to the contact e-mail address, the date of the last update and details of where the site was created. The main site was frame-based and consisted of three separate pages. Two of the pages were fixed, one page holding the company logo while the second was purely for navigation and contained links to the contents of the site. The third page was the main viewing area of the site and was used to display the individual sections of the site. This is achieved by clicking on the links by in the navigational page. When a link is activated it remains highlighted as an indication to the reader that they have already travelled the link. The site took on average 3 seconds to load, which is well within the recommended top limit of 10 seconds. A copy of the site can be found at:

http://osiris.sunderland.ac.uk/ cs0jbt/index 1.htm

\subsection{Client Evaluation of Prototypes and Final development}

To allow the client to view the two initial Web sites a presentation was arranged for Monday the 28th of July 1997. During this presentation the features, design and navigation of each site were demonstrated to the client. A simple form was used to gauge the client feedback. In addition to this further design and content features were discussed and noted. As expected the dummy site served its purpose by demonstrating to the client how the careful design of a site is essential. It was also important to discover that the client was satisfied by the design of the actual proposed site. This meant that further development of the basic design could be continued rather than having to start a new design from scratch.

Following the client evaluation, and appreciative response, further development on the actual site was carried out. The framework of the site was such that 
maintenance and development work was relatively straight forward. Some problems, however, were encountered in providing a "Furniture Suppliers" section. In this section pictures of suppliers' brochures were scanned in and used as an advertisement for their products. Several designs were prototyped but most were abandoned due to the slow speed of the download because of the graphics. It was therefore decided to add a further frame-set to this section. This proved to have a number of advantages over the other possible designs:

- The speed of the download would be vastly improved, as only one graphic

- would be displayed at a time.

- he size of the graphic could be increased due to the faster download speed,

- which would make it easier for readers to view the graphic.

- Readers would be given the option of whether or not to download the graphic.

- Maintenance would be made easier and faster.

The outcome of this decision was that a graphical bulleted list is used as a navigational page and it provides an index of the furniture suppliers. The bullets are all the same, in accordance with the design requirements, as they take a relatively short time to load (compared to that of multiple, different images). The brochure of the supplier is displayed in the adjacent screen, which also displays the name of the supplier. These developments can be viewed at:

http://osiris.sunderland.ac.uk/ cs0jbt/pine/index $1 . \mathrm{htm}$

\section{Evaluation and Conclusions}

In addition to creating the Web site for Principally Pine a Research report on Digital commerce on the Internet was produced. That the sponsor was extremely pleased with both is shown by the following extracts from formal written evaluations:

"I am very pleased with the standard quality of the site. it is simple and easy to use and looks good. All the requirements I originally suggested have been included. I think you have done an excellent job"

"The report provided was very interesting and informative. I cleared up many of the uncertainties I had regarding the subject. The report was easy to follow and understand. I was particularly interested in the sections that discussed encryption and 'Ecash'".McCall (1977)

There have clearly been three winners in this project. they are the sponsoring organisation (Principally Pine), the student and the University:

- Principally Pine have gained not only a trial Web site and the research report but by being closely involved with all stages of the project have gained useful experience and knowledge at minimum cost. There was no charge for the students time. The only expenses the sponsor is expected to meet are any additional costs such as postage, travelling and any necessary software for their 
own machines. They are also obviously expected to provide staff time for consultations and work with the student.

- The student has gained excellent practical experience and has also been able to develop effective research and reporting skills. Working with real clients improves communication skills and it develops the ability to address problems in a professional and efficient manner. The undertaking of such a project also provides a major element of practical experience to be included in a CV when looking for the employment following the course.

- The University has been able to forge a successful link with the business community and has been able to oversee a very effective occurrence of technology transfer. Since both the company and the student were learning together none of the tensions that can arise between consultant and client in a "I know best" situation occurred. Both have been able to develop their knowledge at a reasonable pace over a period of months and work in harmony. The technology transfer from University to the business has occurred almost transparently with the student acting as the catalyst.

In the case of our MSc in Computer Based Information Systems at the University of Sunderland we insist that every project must be "real world" with a sponsor. We do not allow the creation of "pretend" projects by academics as is the case at some other institutions. This forces us to look outside our institution, to make links with the outside world, and give our students real opportunities. This time and time again over the years has proved to be not only to the benefit of the students and the companies, we carry out the projects with, but also to the University itself. By progressing in this way barriers are broken down and the links for further research and constancy are built up. Also one hopes that this will result in the University being the first port of call for advice and help.

\section{References}

Bayne, K. M. (1996) Is your Site a Success? Marketing Tools, March/April.

Chen, P. (1997) Hit-or Miss-Measurement. Counting Hits is Less Than Ideal. Marketing Tools, March.

Gallant, J. (1997) Focus your Site on the Customer. Netmarketing, February 9.

Gantz, J. (1996) Web Site Design: Is It Art or Design. Computerworld, Vol. 30, issue 41, p37.

Green, T. (1996) Daiwa Securities: Trade to the Internet. Bank Systems and Technology, Vol. 35, Issue 10, Oct, p 12.

Greenburg, R. (1996) Psst! Wanna Know How to get your Web Page Noticed. Computerworld, Vol. 30, Issue 41, Oct 7, p100.

Handley, M. \& Crowcroft, J. (1995) The World wide Web - Beneath the Surf. UCL Press. London.

McCall, S. (1997) An Investigation into the use of the Internet as a Medium for Advertising and Trade in a Commercial Environment, MSc. Thesis, School of Computing and Information Systems, University of Sunderland, England.

Oberndorf, S. (1997) Making Web design a Piece of Cake. Catalog Age, Vol. 14, issue 1, Jan, p51. 
Raggett, D. Lam, J. \& Alexander, I. (1996) HTML 3 Electronic Publishing on the World Wide Web. Addison Wesley Longman. England.

Sachs, D. and Stair, H. (1997) The 7 Keys to Effective Web Sites, Computerworld, Vol. 31, Issue 1, Jan 6, p64.

Scheler, R. L. (1996) Baiting the Web. Computerworld, Vol. 30, Issue 28, pp 76-77.

Seltzer, R. (1997) How to Make Business Chat Work. Internet-on-a-Disk, No. 19, February.

Thompson, J. B. and Edwards, H. M. (1995) One Course, Four Delivery /Learning modes and World-Wide Availability: An Example of True Educational Flexibility and Efficiency, Sixth IFIP World Conference Computers In Education, Birmingham.

Thompson, J. B. and Edwards H. M. (1997) The Hybrid Manager: Achievement within a World-Wide Dimension, IFIP WG3.4 International Working Conference, The Place of Information Technology in Management and Business Education, Melbourne Australia, July, 1996, subsequently published by Chapman Hall, Eds Barta B. et al ISBN 0-41279960.

Tilton, E. (1996) Web Weaving: Designing and Managing an Effective Web Site. Database, Vol. 19, Issue 5, Oct/Nov, p 99.

Wilson, S. (1996) World Wide Web Design Guide. Database, Vol. 19, Issue 2, Apr/May, p 103.

\section{Biography}

J. Barrie Thompson is Professor in Applied Software Engineering at the University of Sunderland.

Stuart McCall gained a distinction in the MSc in Computer Based Information Systems at Sunderland University in September 1997, He now works in the computing industry. 